\title{
Comparison of Repeated Video Display vs Combined Video Display and Live Demonstration as Training Methods to Healthcare Providers for Donning and Doffing Personal Protective Equipment: A Randomized Controlled Trial
}

This article was published in the following Dove Press journal: Risk Management and Healthcare Policy

\author{
Yongxing $\mathrm{Li}^{1}, *$ \\ Yong Wangl,* \\ Yuhui $\mathrm{Li}^{\mathrm{I}}$ \\ Ming Zhong ${ }^{\prime}$ \\ Huihui Liu' \\ Caineng $\mathrm{Wu}^{\prime}$ \\ Xiaoqiu Gao' \\ Zhengyuan $\mathrm{Xia}^{2}$ \\ Wuhua $\mathrm{Ma}^{\prime}$ \\ 'Department of Anesthesiology, The \\ First Affiliated Hospital of Guangzhou \\ University of Chinese Medicine, \\ Guangzhou, People's Republic of China \\ ${ }^{2}$ Department of Anesthesiology, The \\ University of Hong Kong, Hong Kong, \\ People's Republic of China \\ *These authors contributed equally to \\ this work
}

Purpose: The lack of training in personal protective equipment (PPE) donning and doffing is hindering the current fight against the COVID-19 worldwide. In order to enable medical staff to learn how to don and doff PPE faster and more effectively, we compared two training methods of PPE donning and doffing.

Methods: Participants in this study were 48 health care workers randomly divided into two groups. Group A watched a 10-minute demonstration (demo) video four times, while Group $\mathrm{B}$ watched the same 10-minute demo video twice and then watched a 10-minute live demo twice. The 40-minute learning time was the same for both groups. A 29-step examination was held after the training was completed. The examination scores of Groups A and B were recorded according to a checklist containing PPE donning and doffing steps. The time spent by the participants on PPE donning and doffing, their satisfaction with the training, and their confidence in donning and doffing PPE accurately were analyzed.

Results: The average score of Group B was higher than that Group A, with a mean (SD) of 94.92 (1.72) vs 86.63 (6.34), respectively $(\mathrm{P}<0.001)$. The average time spent by Group B was shorter than that spent by Group A, with a mean (SD) of 17.67 (1.01) vs 21.75 (1.82), respectively $(\mathrm{P}<0.001)$. The satisfaction and confidence of Group $\mathrm{B}$ were higher than those of Group A $(\mathrm{P}<0.001)$.

Conclusion: Compared with repeated video display, combined video display and live demonstration are more suitable training methods for donning and doffing PPE.

Keywords: COVID-19, coronavirus disease, personal protective equipment, training methods

\section{Introduction}

Health care systems in many countries are facing severe challenges due to the global outbreak of coronavirus disease 2019 (COVID-19) and the consequential exponential growth in the number of patients. According to the World Health Organization (WHO) ${ }^{1}$ as of 31 August 2020, more than 24,854,140 people worldwide had been infected with COVID-19 and 838,924 had already died of the disease. Due to the shortage of personal protective equipment (PPE), a large number of health care workers were also infected with COVID-19. As of
Correspondence: Wuhua Ma Department of Anesthesiology, The First Affiliated Hospital of Guangzhou University of Chinese Medicine, 12 Jichang Road, Guangzhou, Guangdong 510405, People's Republic of China Tel +86-I33I8860680

Email tuesdaymorninggz@I26.com 
8 April 2020, at least 193,825 cases of COVID-19 infected medical staff from 52 countries had been reported. ${ }^{1}$ In the early days of the COVID-19 epidemic, more than 3000 health care workers in China were infected. ${ }^{2}$ As Hubei is the most serious area of the pandemic, a total of 42,600 health care workers have been sent to Hubei Province. However, to date, none of these professionals has been reported to be infected with the new coronavirus. ${ }^{3}$

In the fight against epidemics and pandemics, the provision of PPE for health professionals is essential. However, according to recent studies, training in donning and doffing PPE is also important as its provision. ${ }^{47,8} \mathrm{At}$ the same time, a survey of orthopedic surgeons in Wuhan revealed that participation in real-time training is a key factor in preventing COVID-19 infection. ${ }^{9}$ Thus, the inadequate donning and doffing of PPE by health professionals will not only impair their own protection, but also cause a waste of protective materials, further overloading the already highly impacted health system.

Regarding PPE donning and doffing training methods. According to Christensen et al ${ }^{10}$ and Salway et al, ${ }^{11}$ there is no difference in terms of effectiveness between video display and live demonstrations. While Brockfeld et al ${ }^{12}$ found that video display is as effective as live lectures in medical exams. Klass ${ }^{13}$ believes that electronic courses cannot be separated from practice. However, the existing literature has not yet provided a comparative study to verify whether the use of video display combined with live demonstration is more effective than the use of video display alone as a PPE donning and doffing training method.

To address this gap in the literature, this study aims to investigate the best training method to teach health care workers how to don and doff PPE more quickly and effectively by comparing two training methods widely adopted in health systems worldwide: video display alone and video display combined with live demonstration. This study hypothesized that combined video display and live demonstration is more effective than video display alone. To this end, participants were divided into two groups (one who underwent training using video display combined with live demonstration and one who underwent training using video display alone). Then, all participants underwent a PPE donning and doffing exam following the same procedures. To verify the effectiveness of both methods, this study compared the average scores and the time spent in the PPE donning and doffing exam between the two groups.

\section{Materials and Methods}

\section{Participants}

The study was approved by the Ethics Committee of the First Affiliated Hospital of Guangzhou University of Chinese Medicine (no. ZYYEC-ERK[2020]029) and all participants gave written informed consent. This research was conducted by the Department of Anesthesiology at the First Affiliated Hospital of Guangzhou University of Chinese Medicine, which has 2200 in-patient beds and 2.2 million emergency department visits per year. Participants in this study were 48 physicians and nurses active in the clinical front line of the Department of Anesthesiology who had never participated in PPE donning and doffing training before. The inclusion criterion was to be a medical staff member in the frontline of the COVID-19 pandemics. Exclusion criteria were having experience in PPE donning and doffing, being over 60 years old, having a serious disease, and having recently presented cough or fever. The characteristics of the participants are described in detail in Table 1.

\section{Procedure}

In order to ensure learning efficiency, all participants received a checklist containing PPE donning and doffing steps and the corresponding scores the day before the training (Table 2 and Table 3). This checklist was made according to the video content and the PPE available at the Department of Anesthesiology.

On the training day, first, the 48 participants were ordered by a random sequence of computer-generated numbers, ranging from 1 to 48, which were written on separate pieces of paper. Each participant received one piece of paper with a corresponding order number, and this order would be further followed in the post-training tests. In addition, another 48 pieces of paper were separated for the division of the groups, so that "Group A" was written in 24 pieces and "Group B" in the other 24. Each of the 48 pieces of paper containing the group identifications was placed in a sealed opaque envelope, and all envelopes had the same appearance. The envelopes were shuffled and then numbered 1 to 48. After that, each participant received the envelope with the number corresponding to his/her assigned computer-generated number. After everyone has got the corresponding envelope, opened the envelope at the same time. Thus, the division of participants between Groups $\mathrm{A}$ and $\mathrm{B}$ was done at random and without bias, so that the composition of the groups was not known until each 
Table I Participant Characteristics

\begin{tabular}{|c|c|c|c|}
\hline Variables & Group $A(N=24)$ & Group $B(\mathbf{N}=24)$ & All $(\mathrm{N}=48)$ \\
\hline \multicolumn{4}{|l|}{ Role } \\
\hline Nurse, n (\%) & $3(12.5 \%)$ & $4(16.7 \%)$ & $7(14.5 \%)$ \\
\hline doctor, n (\%) & $21(87.5 \%)$ & $20(83.3 \%)$ & $4 \mathrm{I}(85.5 \%)$ \\
\hline \multicolumn{4}{|l|}{ Gender } \\
\hline Male, n (\%) & II (45.8\%) & $10(41.7 \%)$ & $21(43.7 \%)$ \\
\hline female, n (\%) & 13(54.2\%) & $14(58.3 \%)$ & $27(56.3 \%)$ \\
\hline \multicolumn{4}{|l|}{ Working years } \\
\hline I-5years, n (\%) & $8(33.3 \%)$ & $12(50.0 \%)$ & $20(41.7 \%)$ \\
\hline 5-10years, n (\%) & $9(37.5 \%)$ & $7(29.2 \%)$ & 16(33.3\%) \\
\hline >lOyears, n (\%) & $7(29.2 \%)$ & $5(20.8 \%)$ & $12(25.0 \%)$ \\
\hline \multicolumn{4}{|l|}{ Level of education } \\
\hline Bachelor's degree, n (\%) & $9(37.5 \%)$ & $9(37.5 \%)$ & $18(37.5 \%)$ \\
\hline Master's degree, n (\%) & $13(54.2 \%)$ & $15(62.5 \%)$ & $28(58.3 \%)$ \\
\hline Doctoral degree, n (\%) & $2(8.3 \%)$ & $0(\%)$ & $2(4.2 \%)$ \\
\hline Experience in PPE donning and doffing & 0 & 0 & 0 \\
\hline
\end{tabular}

participant opened his/her own envelope. After the completion of the grouping, Groups A and B went to different rooms for a corresponding 40-minute training session, as follows.

\section{Group A}

Participants went to the video display room to watch the video display. Group A watched a 10-minute video display four times. The training video was provided by the Second People's Hospital of Guangdong Province and can be used by all medical institutions. This 10-minute video was divided into two parts: a five-minute part addressing PPE donning and a five-minute part addressing PPE doffing.

\section{Group B}

Participants went to the live demo room to watch the video display first and then watch the live demo. Group $\mathrm{B}$ watched the 10-minute video display twice and then watched a 10-minute live demonstration twice. The participants were allowed to ask questions while watching the live demonstration. The PPE donning and doffing method was demonstrated by a physician who had received professional and strengthened training prior to the demonstration.

Both groups had a 40-minute learning time and received the same checklist the day before the training. At the end of the training session, participants have a total of 10-minute to familiarize themselves with the equipment. We have prepared enough PPE for group A and group B rooms. Then, all participants went to the exam room and the exams followed the order of the participants numbering (from 1 to 48). Those in charge of the exam were two other physicians who were also professionally trained and who did not know the group compositions at the time of the exam, so as to ensure an unbiased assessment. During the exam, the two physicians assigned scores to participants from different perspectives according to the checklist (Table 2 and Table 3) and then assigned total scores after checking with each other. The steps the participants made mistakes will also be recorded for subsequent analysis. The evaluators and researchers were unable to see to which group each participant belonged, knowing only their sequence number. The results and the corresponding grouping information were collected by other non-researchers following the CONSORT diagram of recruitment (Figure 1).

In both the video display and the live demonstration, two PPE layers were used combined with a powered airpurifying respirator (PAPR). Figure 2 shows the PPE donning process taught to participants to be reproduced by them in the exam according to the checklist in Table 2. The exam consisted of 29 steps corresponding to the 29 in the checklist, each worth a different score ranging from 1 to 6 points, so that each participant could obtain a maximum score of 100 points (Table 2 and Table 3). When the participant was ready, the evaluator would say 'start' and 
Table 2 (Donning): Checklist of PPE Donning and Doffing Key Steps and Their Respective Scores

\begin{tabular}{|c|c|c|}
\hline Step & Content (score: $\mathbf{n}$ points) & Score \\
\hline I & Wash hands, change clothes, check the validity of protective equipment (4 points) & \\
\hline 2 & Wear a disposable hat (no hair exposed) (I point) & \\
\hline 3 & Check the air tightness of the N95 respirator (2 points) & \\
\hline 4 & Wear goggles (I point) & \\
\hline 5 & Wear inner gloves and check the airtightness of gloves ( 4 points) & \\
\hline 6 & Check whether the protective cover-all with hood is damaged and its effective date ( 4 points) & \\
\hline 7 & Wear protective cover-all with hood, zip up, tear open the seal and fasten it from the bottom up ( 6 points) & \\
\hline 8 & Inner gloves are squeezed into the cuffs of the protective cover-all with hood ( 2 points) & \\
\hline 9 & Wear long waterproof boot cover and short waterproof shoe cover (4 points) & \\
\hline 10 & Wear a powered air-purifying respirator (PAPR) and belt (6 points) & \\
\hline 11 & Turn on the power supply and ensure the battery power is sufficient ( 2 points) & \\
\hline 12 & Wear the hood, adjust the position of the hood (with Velcro on the inside) ( 2 points) & \\
\hline 13 & Wear a splash-resistant gown arranged with the help of an assistant (4 points) & \\
\hline 14 & Wear outer gloves (2 points) & \\
\hline 15 & Press the edge of the glove against the sleeve of the splash-resistant gown and secure it with adhesive tape ( 4 points) & \\
\hline 16 & Stretch and squat after wearing, and assistant to check if the skin is exposed ( 2 points) & \\
\hline
\end{tabular}

begin timing the procedure. The time ended when the participant completed the last step of the checklist. The total donning and doffing time was recorded for subsequent analysis. At the end of the exam, participants were given a questionnaire to their satisfaction with the training according to a 5-point Likert scale including: 1 - very dissatisfied; 2 - dissatisfied; 3 - neutral; 4 - satisfied; and 5 - very satisfied. They also assessed how easily they felt they could don and doff PPE according to a 5-point Likert scale including: 1 - very difficult; 2 - difficult; 3 - neutral; 4 easy; and 5 - very easy.

To proceed with the statistical analysis, the primary outcome of this study was the average scores of the two groups, while the secondary outcomes were the time taken by participants to don and doff PPE, their satisfaction with the training, and their perceived ease in PPE donning and doffing.

\section{Statistical Analysis}

In our pilot study which involved 10 participants, the average scores for groups A and B were 85.6 and 94.6, respectively, with a standard deviation (SD) of 6.67 . Considering $90 \%$ power and 0.05 level of significance, we calculated that each group would require 23 participants. Assuming possible dropouts, 48 participants were recruited in this study.

Statistical analysis was performed with the IBM Statistical Product and Service Solutions (SPSS) 23.0 software. $\mathrm{P}<0.05$ was considered to be statistically significant. The measurement data first tested the homogeneity of variance and, if the variance was uniform, a $t$-test of two independent-samples was used to compare the differences between the two groups in average exam scores and time consumed in the procedures. The mean (standard deviation, SD) was used to describe the concentrated trend of the sample and the standard deviation was used to describe the discrete trend of the sample. The data of satisfaction and ease of use were compared using the Wilcoxon signrank test, the median was used to describe the concentrated trend, and the maximum and minimum values were used to describe the discrete trend.

\section{PPE}

Inner layer personal protective equipment: Dupont, Tyvek ${ }^{\circledR}$ Medical disposable personal protective equipment.

Outer personal protective equipment: Disposable Surgical Gown. Cobes Health Care (Hefei) Co., Ltd. B type.

PAPR: Beijing Meijia Yisheng Medical Instruments Co., Ltd, M1-II Helmet.

Gloves: Ansell - Medi-Grip, Latex powder-free gloves, Size 7.

\section{Results}

After the statistics of special personnel, it is found that the average score of Group B was better than that of Group A, 
Table 3 (Doffing): Checklist of PPE Donning and Doffing Key Steps and Their Respective Scores

\begin{tabular}{|c|c|c|}
\hline Step & Content (score: $\mathbf{n}$ points) & Score \\
\hline 17 & $\begin{array}{l}\text { Perform hand hygiene (I point) } \\
\text { Two people spray each other with sodium hypochlorite disinfectant to disinfect the surface of the outer splash- } \\
\text { resistant gown and hood ( } 2 \text { points) }\end{array}$ & \\
\hline 18 & $\begin{array}{l}\text { Perform Hand Hygiene (I point) } \\
\text { Remove splash-resistant gown and outer gloves ( } 3 \text { points) }\end{array}$ & \\
\hline 19 & $\begin{array}{l}\text { Perform hand hygiene ( } 1 \text { point) } \\
\text { Check the airtightness of gloves ( } 2 \text { points) } \\
\text { Wear gloves ( } 2 \text { points) }\end{array}$ & \\
\hline 20 & Take off the outer layer of the waterproof boot cover ( 2 points) & \\
\hline 21 & $\begin{array}{l}\text { Perform hand hygiene (I point) } \\
\text { Enter the second shift strip room, remove the hood carefully (by yourself or with the help of your assistant, and } \\
\text { be careful not to touch the contaminated part of the hood ( } 3 \text { points) }\end{array}$ & \\
\hline 22 & $\begin{array}{l}\text { After performing hand hygiene, remove the PAPR ( } 3 \text { points) } \\
\text { Unfasten the belt, place the belt and power supply on the table covered with disposable towels ( } 2 \text { points), } \\
\text { and put into a double-layer bag ( } 3 \text { points) }\end{array}$ & \\
\hline 23 & Perform hand hygiene (I point) take off outer gloves ( 2 points) & \\
\hline 24 & $\begin{array}{l}\text { Performs hand hygiene ( } I \text { point) take off the protective cover-all with hood and boot cover, tear off the glue, } \\
\text { unzip the zipper, and remove it from the hat ( } 3 \text { points) }\end{array}$ & \\
\hline 25 & $\begin{array}{l}\text { Perform hand hygiene (I point) } \\
\text { Change work shoes ( } 2 \text { points) }\end{array}$ & \\
\hline 26 & $\begin{array}{l}\text { Perform hand hygiene ( } 1 \text { point) } \\
\text { Take off N95 respirator: first remove the lower fixed rope, and then loosen the upper fixed rope ( } 3 \text { points) }\end{array}$ & \\
\hline 27 & $\begin{array}{l}\text { Perform hand hygiene (I point) } \\
\text { Remove the disposable hat }(2 \text { points }) \\
\text { Remove inner gloves ( } 2 \text { points) }\end{array}$ & \\
\hline 28 & $\begin{array}{l}\text { Perform hand hygiene (I point) } \\
\text { Enter the shower, change new hand washing clothes after taking a shower (oral), change personal clothes ( } 2 \\
\text { points) }\end{array}$ & \\
\hline 29 & $\begin{array}{l}\text { In principle, the protective equipment for high-risk medical staff should not exceed } 4 \text { hours per shift (oral) ( } 2 \\
\text { points) }\end{array}$ & \\
\hline 30 & Total score & \\
\hline
\end{tabular}

with a mean (SD) of 94.92 (1.72) vs 86.63 (6.34), respectively $(\mathrm{P}<0.001)$. The average time (in minutes) spent by Group B on donning and doffing PPE was shorter than that spent by Group A, with a mean (SD) of 17.67 (1.01) vs 21.75 (1.82), respectively $(\mathrm{P}<0.001)$. The median satisfaction in Group A was 4.00, while that in Group B was 4.50 $(\mathrm{P}<0.001)$. The median confidence in Group A was 3.00, while that in group B was $4.00(\mathrm{P}<0.001)$ (Table 4). Regarding the donning and doffing procedures, the five steps in which the participants were most likely to make mistakes were: step $10(27.08 \%$ of participants were not very clear on how to use a PAPR), step $3(22.92 \%$ of participants did not check the airtightness of N95), step 27 (in PPE doffing, 22.92\% of participants were contaminated when removing the inner gloves), step 11 (20.83\% of participants did not check the power supply of the PAPR and whether it could be used properly), and step 21 (when doffing the PPE, 20.83\% of participants accidentally touched the contaminated part of the hood). All steps in which participants made mistakes, as well as the number of participants per group and per mistake, are shown in Table 5. 


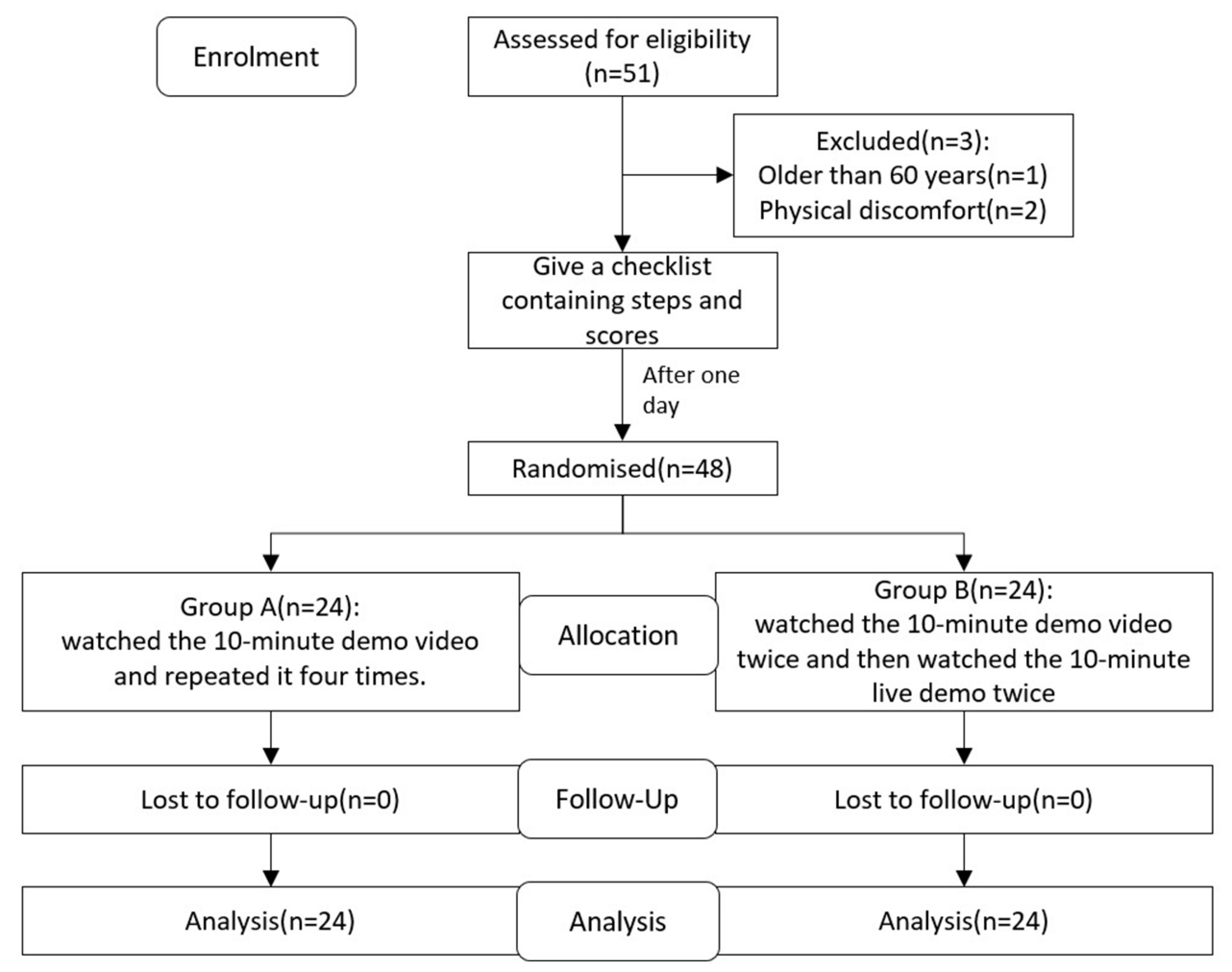

Figure I CONSORT diagram of recruitment.
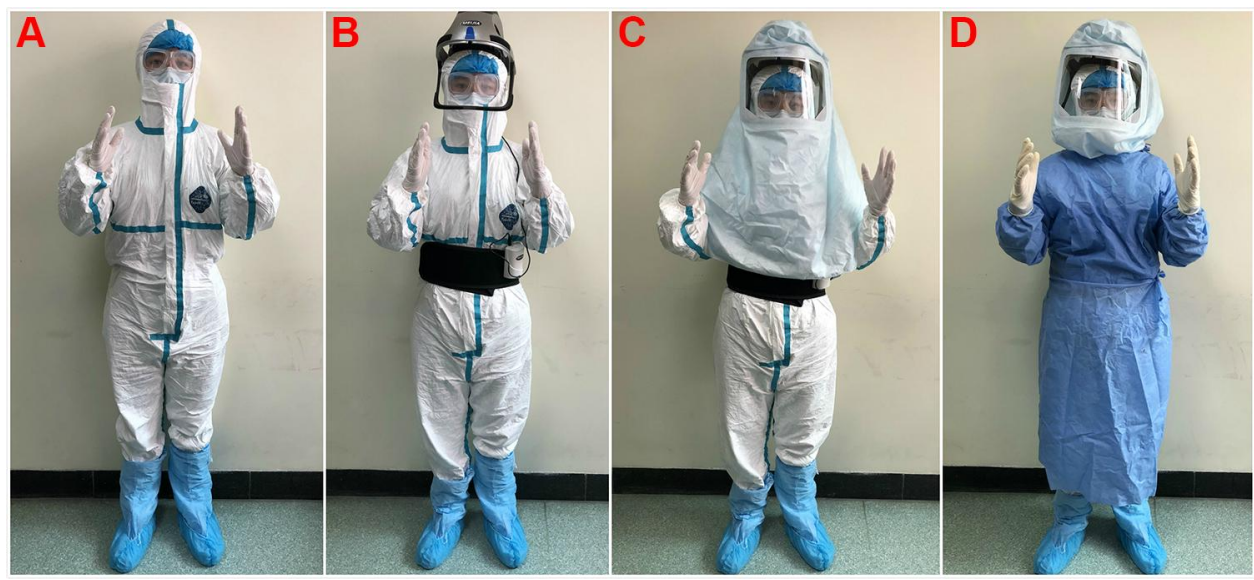

Figure 2 Participant's process of donning personal protective equipment. Two layers of personal protective equipment combined with powered air-purifying respirator (PAPR) (A): the protective cover-all with hood- Inner layer personal protective equipment, (B) Wear a PAPR, (C and D): Outer personal protective equipment with a hood PAPR.

\section{Discussion}

According to the results, the average score of Group $\mathrm{B}$ (combined video display and live demonstration) was higher than that of Group A, while the average time spent by Group B was shorter than that spent by Group A. At the same time, Group B showed greater satisfaction with the training and higher confidence in donning and doffing PPE than Group A. Therefore, the results show that the training method used by Group B is faster and more effective, being therefore more advisable to health care workers.

The significant differences in scores between the two groups in this study led to the conclusion that combined video display and live demonstration is a better training method. However, several studies ${ }^{10,11}$ have indicated that 
Table 4 Comparison Between Scores of Groups A and B

\begin{tabular}{|l|l|l|l|}
\hline & Group A & Group B & $\begin{array}{l}\text { Statistical } \\
\text { Significance }\end{array}$ \\
\hline $\begin{array}{l}\text { The average score of the } \\
\text { exam } \\
\text { Mean (SD) }\end{array}$ & $86.63(6.34)$ & $94.92(\mathrm{I} .72)$ & $\mathrm{P}<0.00 \mathrm{I}$ \\
\hline $\begin{array}{l}\text { Time consuming (Minute) } \\
\text { Mean (SD) }\end{array}$ & $21.75(\mathrm{I} .82)$ & $17.67(\mathrm{I} .0 \mathrm{I})$ & $\mathrm{P}<0.00 \mathrm{I}$ \\
\hline $\begin{array}{l}\text { Participants' satisfaction } \\
\text { Median (Min, Max) }\end{array}$ & $4.00(3,5)$ & $4.50(3,5)$ & $\mathrm{P}<0.00 \mathrm{I}$ \\
\hline $\begin{array}{l}\text { Ease degree } \\
\text { Median (Min, Max) }\end{array}$ & $3.00(2,4)$ & $4.00(3,5)$ & $\mathrm{P}<0.00 \mathrm{I}$ \\
\hline
\end{tabular}

there is no difference between video display and live demonstrations in terms of speed and effectiveness when used solely, proving that both methods alone are equally effective in PPE don and doff. It is noteworthy here that, unlike these studies, we did not set up a group that used only the live demonstration method because we believe that separate solely on-site training does not reflect the current reality, which includes highly developed network and electronic equipment. In addition, the sample size in this study was twice that of Christensen et $\mathrm{al}^{10}$, which gave this study greater potential to identify differences between training methods. Given our pilot study and sample size calculation, we consider that our sample size is reasonable to prove that combined video display and live demonstration is more effective as a training method for PPE donning and doffing. Still on the study sample, the participants were from the department of anesthesiology. In the case of the hospital in this study, these were the frontline personnel in caring for patients with COVID-19 ${ }^{14,15}$, with the highest exposure risk, receiving the least training, and being the most overlooked. Most patients with COVID19 in the hospital who require mechanical ventilation were intubated by anesthesiologists - an operation considered high-risk. This reinforces the significance of our study, as health care professionals with no experience in the use of PPE who are included on the frontlines of combating the pandemic are the ones who most in need effective PPE donning and doffing training methods.

Table 5 Number of Participants Who Made Mistakes in Specific Steps

\begin{tabular}{|c|c|c|c|c|}
\hline Step & Content & $\begin{array}{l}\text { Group } \\
\text { A }\end{array}$ & $\begin{array}{l}\text { Group } \\
\text { B }\end{array}$ & All, $\mathbf{n}(\%)$ \\
\hline 10 & Wear a powered air-purifying respirator (PAPR) and belt. & 10 & 3 & $13(27.08 \%)$ \\
\hline 3 & Check the air tightness of the N95 respirator. & 8 & 3 & II (22.92\%) \\
\hline 27 & Perform hand hygiene, Remove the disposable hat, Remove inner gloves. & 7 & 4 & II (22.92\%) \\
\hline II & Turn on the power supply and ensure the battery power is sufficient. & 8 & 2 & $10(20.83 \%)$ \\
\hline 21 & $\begin{array}{l}\text { Perform hand hygiene, Enter the second shift strip room, remove the hood carefully (by yourself or } \\
\text { with the help of your assistant, and be careful not to touch the contaminated part of the hood. }\end{array}$ & 8 & 2 & $10(20.83 \%)$ \\
\hline 7 & Wear protective cover-all with hood, zip up, tear open the seal and fasten it from the bottom up. & 7 & 2 & $9(18.75 \%)$ \\
\hline 22 & $\begin{array}{l}\text { After performing hand hygiene, remove the PAPR, unfasten the belt, place the belt and power } \\
\text { supply on the table covered with disposable towels, and put into a double-layer bag. }\end{array}$ & 6 & I & $7(14.58 \%)$ \\
\hline 26 & $\begin{array}{l}\text { Perform hand hygiene. Take off N95 respirator: first remove the lower fixed rope, and then loosen } \\
\text { the upper fixed rope. }\end{array}$ & 4 & 2 & $6(12.50 \%)$ \\
\hline 2 & Wear a disposable hat (no hair exposed). & 4 & I & $5(10.42 \%)$ \\
\hline 16 & Stretch and squat after wearing, and assistant to check if the skin is exposed. & 4 & I & $5(10.42 \%)$ \\
\hline 24 & $\begin{array}{l}\text { Performs hand hygiene, take off the protective cover-all with hood and boot cover, tear off the glue, } \\
\text { unzip the zipper, and remove it from the hat. }\end{array}$ & 4 & I & $5(10.42 \%)$ \\
\hline 4 & Wear goggles. & 4 & 0 & $4(8.33 \%)$ \\
\hline 17 & $\begin{array}{l}\text { Perform hand hygiene. Two people spray each other with sodium hypochlorite disinfectant to } \\
\text { disinfect the surface of the outer splash-resistant gown and hood. }\end{array}$ & 4 & 0 & $4(8.33 \%)$ \\
\hline 5 & Wear inner gloves and check the airtightness of gloves. & 2 & I & $3(6.25 \%)$ \\
\hline 6 & Check whether the protective cover-all with hood is damaged and its effective date. & 2 & I & $3(6.25 \%)$ \\
\hline 12 & Wear the hood, adjust the position of the hood (with Velcro on the inside). & 2 & I & $3(6.25 \%)$ \\
\hline 15 & $\begin{array}{l}\text { Press the edge of the glove against the sleeve of the splash-resistant gown and secure it with } \\
\text { adhesive tape. }\end{array}$ & 2 & I & $3(6.25 \%)$ \\
\hline 28 & $\begin{array}{l}\text { Perform hand hygiene. Enter the shower, change new hand washing clothes after taking a shower } \\
\text { (oral), change personal clothes. }\end{array}$ & 2 & I & 3 (6.25\%) \\
\hline
\end{tabular}


In addition to the test scores, time spent on PPE donning and doffing is also crucial. Since, in clinical work, it is necessary to save time on PPE donning and doffing so as to dedicate more time to treating patients. In this sense, the training method used by Group B can save an average of four minutes per donning/doffing procedure than that used by Group A. This time saving is quite significant, especially when rescuing patients. Nevertheless, the average time spent by Group B was 17.67 minutes compared to the 11.61 minutes reported by $\mathrm{Kang}^{16}$ (donning $=7.55$ minutes and doffing $=4.06$ minutes), revealing that there is room for improvement. There are three possible reasons for our longer time. First, our steps are more detailed and safer. Second, all participants were wearing PPE for the first time (we believe that the time spent can be significantly reduced after a few training and practice sections. Therefore, we also arranged the practice section, but after the exam, it was not included in this study). Third, our training time was considerably short, because we selected only the frontline clinical personnel. This approach is more in line with the clinical situation and may allow a better comparison of the differences between the two methods.

It is noteworthy that the PPE used in our study may be different from those used in other countries. We used a protective cover-all with a hood inside and waterproof gowns outside (Figure 2). Our protective cover-all also does not have a thumb-loop cover gown, as in the case reported by Mana et al. ${ }^{17}$ However, we adopted a twoglove technique that would be effective in reducing contamination during PPE doffing. ${ }^{18-20}$ Wearing waterproof boot covers and PAPR ensure that the whole body is protected (Figure 2). Since PPE in China is standardized according to the national standards list of epidemic prevention products, ${ }^{21}$ the steps for donning and doffing PPE are the same in all hospitals, although there is no guideline for donning and doffing other than videos. Since other countries may have different PPE and donning and doffing procedures, it is necessary to don and doff according to the PPE instructions or expert guidelines. In China, there have been no reports of infections among medical staff in facilities where there are sufficient PPE and training. ${ }^{3}$

Among all the steps in which the participants were susceptible to errors, step 10 was the highest in importance and difficulty. A total of 13 participants (27.08\%) did not fully understand how PAPR was used and then made mistakes, because they were receiving training for the first time and had no similar experience before the
COVID-19 pandemic. A short training period is not sufficient for one to quickly master the PAPR usage skills. Therefore, the importance of training should be emphasized, especially with the use of a suitable training method.

In step 21, 10 participants $(20.83 \%)$ made mistakes. It is extremely important to be careful not to touch the contaminated part of the hood, as this results in contamination. When the hood is removed, the neck is contaminated due to improper operation. This can also be attributed to the lack of PAPR training. It is widely known that PPE doffing incurs a very high risk of contamination (Table 3). ${ }^{20}$ According to previous reports, the self-contamination rate can reach between $46 \%$ and $90 \%$ at the time of PPE doffing. ${ }^{18,22}$ Donning and doffing is an integral part of safe PPE use. Therefore, in our clinical practice, when entering or leaving the contaminated area, two medical personnel must go together to remind each other of any possible contamination when removing PPE. In step 27 , there were 11 participants $(22.92 \%)$ who could potentially be contaminated by removing their gloves. Our results are consistent with Tomas et al, ${ }^{18}$ who reported that the contamination rate when removing gloves is as high as $52.9 \%$. One is more likely to be contaminated when removing contaminated gloves than gowns, ${ }^{22}$ and the high pollution rate should not be ignored. The other steps are not discussed here either because they do not considerably differ from our usual work or because they involve small risks of infection. In short, it is necessary to pay more attention to PPE doffing than donning to prevent cross-contamination. ${ }^{23}$

Among all participants, the highest score was 98 points. We believe that the main reasons for this result are the complex PPE donning and doffing procedures, the short training time, and the tension of on-the-spot examination, which eventually lead to mistakes. Therefore, it was not easy for participants to reach 100 points. Our main purpose was to verify which of the two training methods is faster and more effective. However, to ensure safety in clinical practice, all medical staff who may be exposed to COVID-19 must practice the procedure repeatedly according to the best training methods until they reach 100 points in the examination for three consecutive times.

In recent years, with the rapid development of network and electronic equipment, network courses and training are becoming increasingly popular. ${ }^{24-26}$ Because they are convenient and not limited by time and space, web-based courses are preferred by many people, thus being often used as teaching or training resources. Nevertheless, 
Daniel J Klass ${ }^{13}$ believes that electronic courses still cannot be separated from practice. In practical training, webbased courses are often not as impressive as on-site courses, which have unique advantages, such as immersion and interaction. Therefore, in our research, the performance outcomes of a simple video display were not as good as those of combined video display and live demonstration, although the learning time was the same. In addition, Group B showed higher satisfaction than Group A, indicating that, in terms of PPE training, more people still prefer to have on-site teaching, which is in line with the study by Brockfeld. ${ }^{12}$

As COVID-19 is highly contagious, ${ }^{26,27}$ health care providers, including those working in the operating room where surgical trauma may potentially activate latent COVID-19 infection, ${ }^{28}$ are at greater risk. In particular, given the rapid escalation of the spread of COVID-19 worldwide and the lack of a cure, PPE donning and doffing and compliance with protective measures should be emphasized to the utmost. ${ }^{4,6}$ Therefore, our results demonstrating that combined video display and live demonstration is a better training method to teach medical staff how to don and doff PPE faster and more effectively can provide theoretical support for medical staff training.

Despite its valuable contributions, this research has some limitations. First, we did not set up the live demonstration group as a separate group. Thus, we missed the opportunity to compare the live demonstration group with the video group. However, considering the actual clinical situation and other similar studies that have been conducted ${ }^{10,11}$, we believe that it is reasonable not to set up a separate live demonstration group. Because, to ensure accuracy and security in clinical practice, everyone must first watch the standard video regardless of the length of time. Therefore, we can better compare the differences between the two training methods according to clinical practice. Second, the participants recruited were mainly doctors at the Department of Anesthesiology, which may potentially limit the applicability of this study for doctors in ICU or other departments. Participants who voluntarily participate in this study may be those who are more interested in PPE and therefore may have selective bias. They may be more careful when they realize that they are being monitored while taking off the PPE. In addition, we did not set up video recordings and fluorescent markers because our standard videos have been verified by a large number of frontline health care workers. Since our main purpose was to compare the differences between the two training methods, we had no video recordings and fluorescent markers. However, according to the data of the 42,600 medical staff we support in Wuhan, no infection occurs once the steps for donning and doffing PPE are strictly followed. ${ }^{3}$

\section{Conclusion}

After the outbreak of COVID, because of the importance of donning and doffing PPE and we usually lack this kind of training. Therefore, after comparing the simple video display method with the combined video display and live demonstration method, we found that the latter more suitable for medical staff to learn how to don and doff PPE.

\section{Abbreviations}

PPE, personal protective equipment; COVID-19, coronavirus disease 2019; PAPR, powered air-purifying respirator.

\section{Data Sharing Statement}

The datasets used and/or analyzed during the current study are available from the corresponding author on reasonable request.

\section{Ethics Approval and Informed Consent}

The study was approved by the Ethics Committee of the First Affiliated Hospital of Guangzhou University of Chinese Medicine (no. ZYYEC-ERK[2020]029), and all participants gave written informed consent.

\section{Consent for Publication}

All participants had given consent for publication.

\section{Author Contributions}

All authors made substantial contributions to conception and design, acquisition of data, or analysis and interpretation of data; took part in drafting the article or revising it critically for important intellectual content; agreed to submit to the current journal; gave final approval of the version to be published; and agree to be accountable for all aspects of the work. 


\section{Funding}

This work was funded by the National Natural Science Foundation of China (No. 81673922, 81503663,81704167) and the Project of Educational Commission of Guangdong Province of China (No.2018KTSCX037).

\section{Disclosure}

Yongxing $\mathrm{Li}$ and Yong Wang contributed equally to this study. The authors report no conflict of interest in this work.

\section{References}

1. World Health Organization. Coronavirus disease (COVID-19) pandemic. Available from: https://www.who.int/emergencies/dis eases/novel-coronavirus-2019. Accessed October 03, 2020.

2. Li N, Yu X. Outbreak and regression of COVID-19 epidemic among chinese medical staff. Risk Manag Healthc Policy. 2020;13:1095-1102. doi: $10.2147 / \mathrm{rmhp} . \mathrm{S} 268178$

3. Health Commission of Hubei Province. None of the 42,600 medical team members assisting Hubei was infected. Available from: http:// wjw.hubei.gov.cn/bmdt/ztzl/fkxxgzbdgrfyyq/fkdt/202003/ t20200309_2175909.shtml. Accessed October 03, 2020.

4. Gerada C. Clare Gerada: doctors on the covid-19 front line also need to protect themselves and their colleagues. BMJ. 2020;368:m1121. doi:10.1136/bmj.m1121

5. Li L, Xv Q, Yan J. COVID-19: the need for continuous medical education and training. Lancet Respir Med. 2020;8(4):e23. doi:10.1016/S2213-2600(20)30125-9

6. Rimmer A. Covid-19: BMA calls for rapid testing and appropriate protective equipment for doctors. BMJ. 2020;368:m1099. doi:10.1136/bmj.m1099

7. The Lancet. COVID-19: protecting health-care workers. Lancet. 2020;395:10228. doi:10.1016/s0140-6736(20)30644-9

8. Ma W, Wang Y. Personal protective equipment and Covid-19. N Eng $J$ Med. 2020;383(4):e22. doi:10.1056/NEJMc2021986

9. Guo X, Wang J, Hu D, et al. Survey of COVID-19 disease among orthopaedic surgeons in Wuhan, People's Republic of China. J Bone Joint Surg Am. 2020;102(10):847-854. doi:10.2106/jbjs.20.00417

10. Christensen L, Rasmussen CS, Benfield T, Franc JM. A randomized trial of instructor-led training versus video lesson in training health care providers in proper donning and doffing of personal protective equipment. Disaster Med Public Health Prep. 2020;1-15. doi:10.1017/dmp.2020.56

11. Salway RJ, Williams T, Londono C, Roblin P, Koenig K, Arquilla B. Comparing training techniques in personal protective equipment use. Prehosp Disaster Med. 2020;35(4):364-371. doi:10.1017/S104 9023X20000564

12. Brockfeld T, Müller B, de Laffolie J. Video versus live lecture courses: a comparative evaluation of lecture types and results. Med Educ Online. 2018;23(1):1555434. doi:10.1080/10872981.2018.1555434

13. Klass DJ. Will e-learning improve clinical judgment? BMJ. 2004;328 (7449):1147-1148. doi:10.1136/bmj.328.7449.1147
14. Yao W, Wang T, Jiang B, et al. Emergency tracheal intubation in 202 patients with COVID-19 in Wuhan, China: lessons learnt and international expert recommendations. Br J Anaesth. 2020;125(1):e28e37. doi:10.1016/j.bja.2020.03.026

15. Lee D, Ma M, Parotto M, Wąsowicz M. Intubation outside of the operating room: new challenges and opportunities in COVID-19 era. Curr Opin Anaesthesiol. 2020;33(4):608-611. doi:10.1097/ACO.000 0000000000892

16. Kang J, O’Donnell JM, Colaianne B, Bircher N, Ren D, Smith KJ. Use of personal protective equipment among health care personnel: results of clinical observations and simulations. Am J Infect Control. 2017;45(1):17-23. doi:10.1016/j.ajic.2016.08.011

17. Mana T, Tomas ME, Cadnum JL, Jencson AL, Piedrahita CT, Donskey CJ. A randomized trial of two cover gowns comparing contamination of healthcare personnel during removal of personal protective equipment. Infect Control Hospital Epidemiol. 2018;39 (1):97-100. doi:10.1017/ice.2017.249

18. Tomas ME, Kundrapu S, Thota $\mathrm{P}$, et al. Contamination of health care personnel during removal of personal protective equipment. JAMA Intern Med. 2015;175(12):1904-1910. doi:10.1001/jamainternmed.2015.4535

19. Casanova L, Rutala W, Weber D, Sobsey M. Effect of single- versus double-gloving on virus transfer to health care workers' skin and clothing during removal of personal protective equipment. $\mathrm{Am}$ J Infect Control. 2012;40(4):369-374. doi:10.1016/j.ajic.2011.04.324

20. John TJ, Hassan K, Weich H. Donning and doffing of personal protective equipment (PPE) for angiography during the COVID-19 crisis. Eur Heart J. 2020;41(19):1786-1787. doi:10.1093/eurheartj/ehaa283

21. Standardization Administration of the P.R.C. Chinese national standards list of epidemic prevention products. Available from: http:// www.sac.gov.cn/sacen/FAC/SLOCEPP/202004/t20200414_346413. htm. Accessed October 03, 2020.

22. Osei-Bonsu K, Masroor N, Cooper K, et al. Alternative doffing strategies of personal protective equipment to prevent self-contamination in the health care setting. Am J Infect Control. 2019;47(5):534-539. doi:10.1016/j.ajic.2018.11.003

23. Baloh J, Reisinger HS, Dukes K, et al. Healthcare workers' strategies for doffing personal protective equipment. Clin Infect Dis. 2019;69 (Supplement_3):S192S198. doi:10.1093/cid/ciz613

24. de Sena D, Fabrício D, da Silva V, Bodanese L, Franco A. Comparative evaluation of video-based on-line course versus serious game for training medical students in cardiopulmonary resuscitation: a randomised trial. PLoS One. 2019;14(4). doi:10.1371/journal.pone.0214722

25. Perkins GD, Kimani P, Bullock I, et al. Improving the efficiency of advanced life support training: a randomized, controlled trial. Ann Intern Med. 2012;157(1):19-28. doi:10.7326/0003-4819-157-1-201207 030-00005

26. Almaghaslah D, Alsayari A. The effects of the 2019 Novel Coronavirus Disease (COVID-19) outbreak on academic staff members: a case study of a pharmacy school in Saudi Arabia. Risk Manag Healthc Policy. 2020;13:795-802. doi:10.2147/RMHP.S260918

27. Jiang F, Deng L, Zhang L, Cai Y, Cheung CW, Xia Z. Review of the clinical characteristics of coronavirus disease 2019 (COVID-19). J Gen Intern Med. 2020;35(5):1545-1549. doi:10.1007/s11606-020-05762-w

28. Lei S, Jiang F, Su W, et al. Clinical characteristics and outcomes of patients undergoing surgeries during the incubation period of COVID-19 infection. E Clin Med. 2020;21:100331. doi:10.1016/j. eclinm.2020.100331 


\section{Publish your work in this journal}

Risk Management and Healthcare Policy is an international, peerreviewed, open access journal focusing on all aspects of public health, policy, and preventative measures to promote good health and improve morbidity and mortality in the population. The journal welcomes submitted papers covering original research, basic science, clinical \& epidemiological studies, reviews and evaluations, guidelines, expert opinion and commentary, case reports and extended reports. The manuscript management system is completely online and includes a very quick and fair peer-review system, which is all easy to use. Visit http://www.dovepress.com/testimonials.php to read real quotes from published authors.

Submit your manuscript here: https://www.dovepress.com/risk-management-and-healthcare-policy-journal 